\title{
ALTRUISM EXCHANGES AND THE KIDNEY SHORTAGE
}

\author{
STEPHEN J. CHOI* \\ Mitu GULATI** \\ ERIC A. POSNER *** \\ I \\ INTRODUCTION
}

Increasing the number of kidney donations is an urgent matter. There is a disparity between the number of patients in the United States who are in need of kidney transplants and the availability of kidneys to be transplanted. In any given year, as many as 100,000 Americans need a kidney transplant, while fewer than 20,000 will receive them from live or cadaveric donors. ${ }^{1}$ It is not uncommon for patients to get so sick while waiting to receive a kidney that they are unable to receive one at all, even if it eventually becomes available. ${ }^{2}$

Some economists believe that the solution to this problem is to permit people to buy and sell kidneys. ${ }^{3}$ On the demand side, people with chronic kidney disease suffer from acute distress as well as increased mortality. Many of them would be willing to pay for a new kidney, especially if the price were not too high. And even for those who would not be able to afford a new kidney, their insurers would likely be willing to pay for one because the price of a kidney would likely be less than the cost of medical care for end-stage renal disease, including the expense of dialysis treatments. ${ }^{4}$

Copyright (C) 2014 by Stephen J. Choi, Mitu Gulati, and Eric A. Posner.

This article is also available at http://lcp.law.duke.edu/.

* Murray and Kathleen Bring Professor of Law and Director of the Pollack Center, New York University.

** Professor of Law, Duke University.

*** Kirkland \& Ellis Distinguished Service Professor of Law and Aaron Director Research Scholar, the University of Chicago. Thanks to Ellie Norton for research assistance. Thanks to Alexander Berger, Phil Cook, Prea Gulati, Judd Kessler, Debra Satz, Kim Krawiec, and participants at the Organs and Inducements symposium at Duke University for comments.

1. See Philip J. Cook \& Kimberly D. Krawiec, A Primer on Kidney Transplantation: Anatomy of the Shortage, 77 LAW \& CONTEMP. PROBS., no. 3, 2014, at 1.

2. Id.

3. See Gary S. Becker \& Julio J. Elías, Cash for Kidneys: The Case for a Market in Organs, WALL ST. J. (Jan. 18, 2014), http://online.wsj.com/news/articles/SB10001424052702304149404579322560 004817176; Gary S. Becker \& Julio Jorge Elías, Introducing Incentives in the Market for Live and Cadaveric Organ Donations, J. ECON. PERSP., Summer 2007, at 3.

4. See David Tuller, Lifesaving Kidney Treatment, but Only to a Point, N.Y. TIMES (Mar. 12, 2009), http://www.nytimes.com/2009/03/13/health/13kidney.html?_r=0 (estimating the cost of a kidney transplant at over $\$ 100,000$, but the cost of dialysis at over $\$ 70,000$ per year). 
On the supply side, some people already donate kidneys for free ${ }^{5}$ and, given standard assumptions about behavior, it is likely that additional people would be willing to sell a kidney for a high enough price. Black markets in other countries suggest as much, and there are estimates indicating that the market would clear at about $\$ 150,000$ paid per kidney. ${ }^{6}$ Some might also be willing to accept a small payment in return for the commitment to donate their kidneys at the time of death. Others might wish to "sell" their kidneys at death, with the proceeds going to heirs.

But a legal market in kidneys will not come into existence in the foreseeable future. People harbor strong moral intuitions against buying and selling human organs, ${ }^{7}$ and these intuitions have been embodied in law. ${ }^{8}$ The National Organ Transplant Act (NOTA) of 1984 prohibits the knowing acquisition, receipt, or transfer of any human organ for "valuable consideration for use in human transplantation." Consideration is a legal concept that undergirds contract law, meaning "a bargained for exchange, of a promise for a promise, or a promise for a performance." 10 Thus, a person may not transfer a kidney to another person in return for anything of value, such as money; nor may a person receive a kidney in return for anything of value.

But consideration is a slippery doctrine, and the kidney shortage has given rise to creative efforts to narrow the scope of NOTA's prohibition so as to enhance the supply of kidneys. For example, donors are allowed to direct that their kidneys be given to certain people: family members, friends, and others. This might seem like a transfer without valuable consideration, but that is not necessarily the case. The donor might transfer to such people rather than to a

5. The number has varied between 100 and 200 per year over the last several years. Transplants by Donor Type, U.S. DEP'T HEALTH \& HUM. SERVICES, http://optn.transplant.hrsa.gov/latestData/ step2.asp? (last updated Nov. 1, 2013) (request a report for category "transplant" and organ "kidney," select "transplant by donor type," add a field for "donor relation," and then consult table under the heading "Non-Biol, unrel: Anonymous Donation").

6. The average price paid to the seller of a kidney in the black market is lower, at $\$ 5000$ per kidney. Prices and Costs of Black Market Organs and Kidney Transplants, HAVOCscoPe, http://www.havocscope.com/black-market-prices/organs-kidneys/ (last visited Oct. 9, 2013).

7. See generally EliZABETH ANDERSON, VALUE IN ETHICS AND ECONOMICS (1995); MiCHAEL J. Sandel, What Money Can't Buy (2012); Debra Satz, Why Some Things Should Not Be FOR SALE: THE MORAL LIMITS OF MARKETS (2010).

8. See Flynn v. Holder, 684 F.3d 852, 860-61 (9th Cir. 2012) (discussing the various concerns); Julia D. Mahoney, Altruism, Markets, and Organ Procurement, 72 LAW \& CONTEMP. ProBs. 17, 22-30 (Summer 2009) (noting the hostility towards using financial considerations to motivate organ donations).

9. 42 U.S.C. $\S 274 \mathrm{e}$ (2006). Responding to technological and medical advances that made organ transplants easier to perform effectively, Congress sought to restrict the development of a market for organs (specifically, kidneys). See generally H.R. REP. NO. 98-1127 (1984); S. REP. NO. 98-382 (1984). In hindsight, we know that Congress was unduly optimistic about the level of altruistic donations that would take place. See generally S. REP. NO. 98-382.

10. See Robert E. SCOTT \& Jody S. Kraus, ConTract LAW AND TheOry 41 (4th ed. 2007). NOTA uses the term "valuable consideration" so as to exclude the reimbursement of donors for reasonable costs incurred in the process of donating. 42 U.S.C. $§ 274 \mathrm{e}(\mathrm{c})(2)$; see also S. REP. No. 98-382, at 16 . 
stranger because she expects to receive something in return-for example, household services or help in some other matter. Only a donation to an anonymous stranger could clearly be without consideration. Nonetheless, the common law of contract generally treats intrafamily transfers as occurring without consideration, and regulated entities and regulators have apparently taken this position for kidney donations to friends and family, as well. ${ }^{11}$ The acceptance of this fiction has been crucial to increasing the supply of live kidney donations in particular; in 2012, over ninety-five percent of all live kidney donations came from family members or friends. ${ }^{12}$

One reason for the acceptance of this practice might be that donations that are either altruistically motivated or that take place within close relationships do not raise the specter of a "market" in kidneys, where the poor are exploited and the human body is commodified. As we will see, however, the moral and policy considerations are complex.

The transfer of kidneys also takes place through an arrangement known as a paired-kidney exchange involving two pairs of donor-recipients. Paired-kidney exchanges address a common problem that arises when a person is willing to donate her kidney to a potential recipient but there is no match, so that, without some solution, the kidney would be rejected. Sometimes, doctors can find another potential donor-recipient pair with the same problem, and the donors in each pair are compatible with the recipients of the other pair. For example, Donor 1 would like to donate to Recipient 1, but instead donates to Recipient 2 while Donor 2 donates to Recipient 1.

This transaction would almost certainly be regarded as a classic contractual exchange with consideration. Donor 1 promises his kidney to Recipient 2, in exchange for consideration, which consists of Donor 2's promise to transfer her kidney to Recipient 1 . It is true that the transfer back to Donor 1 consists of a benefit to someone else. But consideration exists even when the recipient does not receive a benefit; it is sufficient that the giver of a good, service, or promise undergoes a detriment, which the loss of a kidney certainly is to the donor. Compare a transaction in which Donor 1 forgives a debt to Recipient 2 in return for which Donor 2 forgives a debt to Recipient 1 . Courts would enforce this transaction, regardless of whether the underlying motivations are commercial or altruistic.

The Department of Health and Human Services agreed that pair exchanges might involve the exchange of "valuable consideration."13 As a result, hospitals

11. See, e.g., MAlcolm E. Ritsch, JR., United Network FOR ORGAn Sharing, INTENDED RECIPIENT EXCHANGES, PAIRED EXCHANGES AND NOTA $\S 301$, at 3 (2003), available at http://www.stanford.edu/ alroth/UNOS.2003LegalOpinion.Section_301_NOTA_.pdf (analyzing the applicability of NOTA section 301 to kidney donations, and finding that "'[v]aluable consideration' under NOTA $\$ 301$ is a monetary transfer or a transfer of valuable property between donor, recipient and/or organ broker in a sale transaction. It is not familial, emotional, psychological or physical benefit to the organ donor or recipient ....").

12. See Cook \& Krawiec, supra note 1, at Figure 8.

13. John A. Schall, Congress Passes Legislation on Paired Kidney Donation, AM. Ass'N KIDNEY 
were initially unwilling to perform pair-exchange transplants. ${ }^{14}$ For this reason, Congress passed the Charlie W. Norwood Living Organ Donation Act ("The Norwood Act"), which provides that a kidney exchange does not involve the exchange of consideration as a legal matter. ${ }^{15}$ Thus, kidney exchanges were taken outside the ambit of NOTA.

The apparent moral acceptance of kidney exchanges embodied in the Norwood Act suggests that the objection to a kidney "market" does not lie in the existence of exchanges of consideration per se, even when the exchange takes place between strangers. Instead, the objection appears to lie with the motivation behind the sale of kidneys for cash. In the case of an altruistic donation, donors can benefit only from the improvement of the well-being of the recipients, and not from pecuniary compensation. Concerns about market transactions resulting in the commodification of humans are not implicated. Moreover, poor people cannot enter a paired exchange to make money, and so this source of coercion is absent. The altruistic element seems to take these transactions outside the realm of the type of market transactions that many find repugnant. ${ }^{16}$

The discussion so far has only touched on difficult moral issues, but it suggests that the usual debate about whether people should be allowed to sell kidneys is too starkly drawn. There are degrees between a pure donation of a kidney on the one hand and a sale on the other, and moral intuitions might permit transactions that fall between the two extremes, like the paired-kidney exchange. The purpose of this article is to press on this ambiguity, and to propose further intermediate transactions that do not offend moral intuitions and thus will expand the supply of kidneys.

In this article we present three proposals. First, we argue for an expansion of the range of altruistic donations that may be exchanged for a kidney donation (including non-kidney-related charitable donations of other organs, goods, and services). Second, we argue for the use of monetary transfers in altruistic exchanges. Lastly, we explore the role of intermediaries in assisting altruistic exchanges. We propose that charities create "altruism exchanges," intermediaries that enable people to donate kidneys (and other things) in return for a commitment by others to make charitable donations or engage in charitable acts.

In part II we survey the current forms of kidney exchanges allowable under NOTA and the moral debate about kidney markets. In part III we present our

PATIENTS, https://www.aakp.org/advocacy/public-policy/item/congress-passes-legislation-on-pairedkidney-donation.html (last visited Dec. 30, 2013).

14. Id.

15. Charlie W. Norwood Living Organ Donation Act, Pub. L. No. 110-144, 121 Stat. 1813 (2007) (codified at 42 U.S.C. $\S \S 273 b, 274$ e (2006 \& Supp. IV 2011)).

16. See generally LEON R. KASS, LIFE, LiBERTY AND THE DEFENSE OF Dignity: The Challenge FOR BIOEThics 177, 182-85 (2002); Alvin E. Roth, Repugnance as a Constraint on Markets, J. ECON. PERSP., Summer 2007, at 37 (examining "repugnant" transactions and consequences of repugnance, especially in relation to buying and selling kidneys). 
three proposals. In part IV we discuss the legal implications of our proposals, and in part $\mathrm{V}$ we conclude.

II

\section{BACKGROUND ON KIDNEY DONATION, KIDNEY MARKETS, AND THE LAW}

NOTA prohibits the transfer of a human organ for "valuable consideration for use in human transplantation if the transfer affects interstate commerce."17 Transfers of kidneys that are not made for "valuable consideration" are allowable under NOTA. ${ }^{18}$

Contract scholars are familiar with the concept of consideration but many readers will not be. In contract law, a promise is (generally speaking) enforceable as a legal obligation only if it is motivated by bargained-for consideration. ${ }^{19}$ This means that the person who makes the promise does so in order to induce the other person (the promisee) to do something. The classic example is an ordinary sale, as shown in Figure 1.

Figure 1

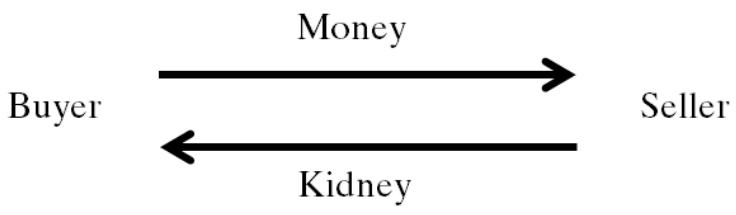

If the seller were to promise an ordinary good or service, this contract would be enforceable. The seller's promise to deliver the good or service is consideration for the buyer's promise to pay money, and the buyer's promise to pay money is consideration for the seller's promise to deliver the good or service. Of course, because the seller in our example promises her kidney, the contract is unenforceable.

At the opposite extreme of an ordinary sale is the gratuitous promise, when a donor promises something to a donee in return for nothing, as shown in Figure 2.

Figure 2

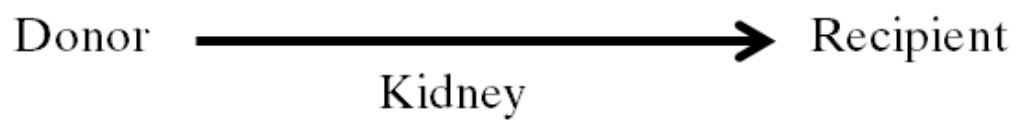

17. 42 U.S.C. $\$ 274 \mathrm{e}(2006)$.

18. Id.

19. SCOTT \& KRAUS, supra note 10 . 
Under the common law of contract, the donee is not permitted to enforce the donor's promise if the donor decides not to perform. However, if the donor does perform, the transfer of the gift is valid and enforceable.

NOTA bans the sale shown in Figure 1, but not the donation shown in Figure 2. Two justifications are commonly given for the ban. First, the sale of kidneys commodifies the human body, treating a person as a container of "spare parts." ${ }^{20}$ Second, burdens of a for-profit kidney market would fall disproportionately on the poor, who will be more likely to sell their kidneys for profit than the wealthy. ${ }^{21}$

Although both justifications are assumed to be correct for the purpose of this article, they are not self-evident. Proponents of the commodification objection have not explained why the sale of an organ is morally offensive in itself. It is possible that objections reflect an inarticulate sense of disgust, much as in vitro fertilization and surrogacy contracts once did, rather than legitimate moral concerns. ${ }^{22}$

The objection rooted in concern for the poor is questionable because normally one would expect the poor to benefit more than the wealthy from the expansion of market opportunities. In this case, poor people would more likely need the money they could gain from selling their kidneys than rich people would. Critics of kidney markets argue that for precisely this reason the poor are likely to be coerced. The poor lack the information and sophistication to make good decisions regarding kidney sales. ${ }^{23}$ But this objection is one to markets generally, not to kidney markets. One could make the same argument about, say, credit markets, where poor people often make bad decisions because of coercion and lack of sophistication. But no one wants to eliminate credit markets in order to protect poor people. If poor people are susceptible to exploitation, they can simply be forbidden from selling their kidneys, just as usury and related laws are used to restrict the extension of credit to the poor. Under such a scheme, poor people (and everyone else) would benefit from having the ability (through insurance) to buy kidneys sold by non-poor people

20. See S. REP. No. 98-382, at 17 (1984); National Organ Transplant Act: Hearing on H.R. 4080 Before the Subcomm. on Health of the H. Comm. on Ways \& Means, 98th Cong., 2d Sess. 26 (1984) (statement of Rep. Henry A. Waxman, Member, H. Subcomm. on Health \& the Env't, H. Comm. on Energy \& Commerce). There is a growing literature debating whether markets for organs should be permitted. See generally, JAMES STACEY TAYLOR, STAKES AND KIDNEYS: WHY MARKETS IN HUMAN Body PARTS ARE MORAlly IMPERATIVE (2005); Benjamin Hippen et al., Saving Lives Is More Important Than Abstract Moral Concerns: Financial Incentives Should Be Used to Increase Organ Donation, 88 AnNALS THORACIC SuRgery 1053 (2009); Gilbert Meilaender, Gifts of the Body, 13 NEW ATLANTIS 25 (2006).

21. See, e.g., Dan Bilefsky, Black Market for Body Parts Spreads Among the Poor in Europe, N.Y. TIMES, June 29, 2012, at A8 (detailing the story of an unemployed father who put his kidney up for sale to support his family).

22. See Roth, supra note 16, at 39, 43; see also Patricia Cohen, Economists Dissect the 'Yuck' Factor, N.Y. TIMES, Jan. 31, 2008, at E1 (discussing repugnance in the marketplace and noting that paying for sperm and eggs for fertilization is common practice, but the sale of tissue, cells, and organs is still disputed).

23. See SATZ, supra note 7, at 195-97. 
who would like the extra money. It is unclear why people (rich and poor) should have to die or suffer through dialysis to protect (some) poor people from bad choices.

In any event, these harms are associated with the for-profit sale of kidneys, not altruistic donations. NOTA embodies a "congressional concern with the buying and selling of human organs for profit, rather than an attempt to prohibit all transactions in human organs that involve some element of exchange." ${ }^{24}$ In the Norwood Act, Congress made clear that NOTA's prohibition of the exchange of valuable consideration for human organs does not apply to simultaneous, paired, altruistic exchanges of kidneys. The underlying thinking must be that poor people will not be tempted to donate their organs unless they are given a financial incentive; or, if they donate their organs for altruistic reasons, that choice should be respected. Congress, in other words, displayed a preference for increasing the supply of organs available for donation so long as the increase was compatible with protecting the interests of the poor.

The most altruistic form of kidney donation is the pure gift in which a donor gives her kidney without any expectation of financial or nonfinancial consideration-such as a donation of a kidney to a complete stranger. As noted above, matters are more complex when a person transfers a kidney to a relative or close friend. ${ }^{25}$ Although altruism might motivate such a donation in part, other factors likely also motivate the donation. For example, when a friend "donates" money to another friend to purchase a car, the motivation might be altruistic but it need not be, because the donor might expect return favors in the future. Nonetheless, the law does not treat a transfer or promise made with the expectation of an unspecified return transfer as motivated by consideration. Thus, it appears that "commodification" does not take place when exchanges occur within close relationships, and that the poor, in particular, will not normally be coerced to enter into such transactions. ${ }^{26}$

Many kidney donations, however, do not follow the model of the one-sided donation to a stranger or friend. It frequently happens that one person wants to donate a kidney to another, but the intended recipient is unable to receive the kidney because of immune-system incompatibility. The particular donorrecipient pair will then find another donor-recipient pair where the first donor's kidney matches with the second recipient and vice versa. The pair then exchanges kidneys simultaneously. Donor 1 gives his kidney to Recipient 2; Donor 2 gives her kidney to Recipient 1. Figure 3 depicts this transaction.

24. Kieran Healy \& Kimberly D. Krawiec, Custom, Contract, and Kidney Exchange, 62 DuKE L.J. 645, 661 (2012).

25. See supra Part I.

26. This is not to say that the pressures to donate within a familial setting might not be coercive. But this problem is not unique to the poor. Our point in the present context is that another source of coercion-money-is absent. 
Figure 3

Donor 1 Donor 2

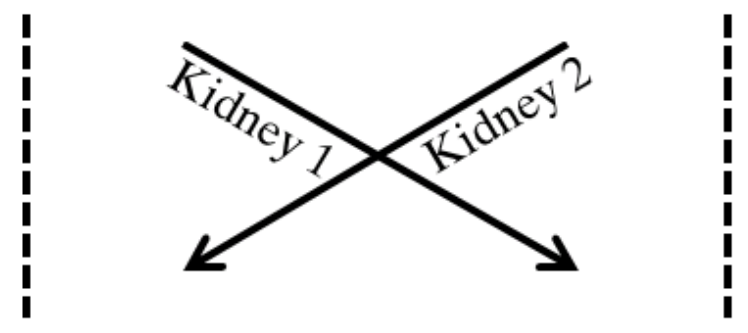

Recipient $1 \quad$ Recipient 2

Although such an exchange is (or might be) motivated by altruistic desires on the part of both donors, it is still an exchange. Each donor gives up a kidney so that the other donor gives up a kidney. The law would probably not regard each donor as receiving a "benefit" because the donor does not receive anything in return, but giving up a kidney is a "detriment," and thus still qualifies as consideration.

Presumably in response to concerns that such exchanges violate NOTA, Congress passed the Norwood Act, which provided that a kidney exchange does not count as an exchange for "valuable consideration." ${ }^{\text {"27 }}$ Congress could have said a kidney exchange is lawful even though valuable consideration is exchanged; instead, it said that a kidney exchange does not involve the exchange of valuable consideration. This distinction is important. Congress must have believed that two aspects of organ exchange bother people: (1) a market-like "exchange," and (2) profit seeking as a motivation for such exchanges. The Norwood Act reveals that Congress was willing to relax the rule against exchanges, making clear that the real motivation for bans on organ markets is opposition to self-interested or for-profit organ transfers as opposed to altruistic organ transfers.

Recent innovations in kidney exchanges have relied on the notion that altruistically motivated exchanges do not run afoul of Congress's intent in NOTA and thus should also benefit from the legal fiction that such exchanges are not for valuable consideration. The newest forms of exchanges involve nonsimultaneous, extended, altruistic-donor (NEAD) chains. ${ }^{28}$ One altruistic donor starts a NEAD chain with a one-sided donation to a stranger, typically with no expectation of anything in return. After this first altruistic donor, however, NEAD chains involve a series of exchanges in which one donor transfers her

27. Charlie W. Norwood Living Organ Donation Act, Pub. L. No. 110-144, 121 Stat. 1813 (2007) (codified at 42 U.S.C. $\S \S 273 b$, 274e (2006 \& Supp. IV 2011)).

28. On the dynamics of NEAD chains, see Kimberly D. Krawiec \& Michael Rees, Reverse Transplant Tourism, 77 LAW \& CONTEMP. PROBS., no. 3, 2014 at 145. 
kidney to another recipient only after receiving a kidney for her particular recipient. Instead of having a mutual exchange between two matching pairs of donor-recipients, a NEAD chain involves serial exchanges across otherwise unconnected donor-recipient pairs. Much like a mutual exchange, the NEAD chains are motivated by altruism on the part of the donor (to aid her particular recipient) and thus also arguably fall under the legal fiction that such exchanges do not involve "valuable consideration" despite the more extended nature of such exchanges for consideration. ${ }^{29}$

Other possible altruistic exchanges exist. Some donors might desire to timeshift their donations. A father of a child with kidney disease might want to donate his kidney to the child, but might not have the need to do so for many years. Looking ahead, the father might worry that when his child needs a kidney, he will be too old to be a viable donor. The father might therefore desire to donate his kidney to a recipient today in return for a donation to his child at some point in the future. Alternatively, he might be willing to donate his kidney in exchange for his child being given priority on the waiting list for available kidneys. ${ }^{30}$ What distinguishes altruistically motivated exchangeswhether involving two matching donor-recipient pairs, chains of kidney exchanges, or time-banking exchanges-is the underlying motivation behind such transactions. The donor is motivated not by an immediate financial gain, but instead by a desire to make a donation of her kidney to another person that-because of tissue incompatibility or a time-shifting problem-is not feasible without such a kidney exchange.

The next stage of this series of efforts to expand the supply of kidneys in the face of legal constraints moves beyond altruism. Lifesharers is a nonprofit organization that brings together organ donors who agree to donate their organs upon their own death in return for first access to the organs of other Lifesharers members. ${ }^{31}$ Donations through the Lifesharers program involve both consideration (the donor receives the right to first access in return for the donation) and self-interest (the donor benefits himself rather than another by obtaining first access). The program stops short of a full-fledged market, however, because it does not allow donors to receive pecuniary compensation. The program is, in effect, a for-profit (albeit in-kind, rather than financial) barter market. Lifesharers goes too far, however, because it involves no altruism on the part of the donor, and thus violates NOTA.

Lifesharers is (or likely will be) a cautionary tale about the limits of the law

29. See Healy \& Krawiec, supra note 24 (discussing NEAD chains and their relationship to gift exchange).

30. In some countries, consent to donations of organs upon death is the default presumption. Those who take themselves off the presumed consent list are given a lower priority, should they need to be on the queue themselves. See Judd B. Kessler \& Alvin E. Roth, Organ Allocation Policy and the Decision to Donate, 102 AM. ECON. REV. 2018, 2020-21 (2012) (finding, in the context of an experimental setting, a significant impact of the use of priority schemes on the likelihood of registration for organ donation).

31. See LiFESHARERS, http://www.lifesharers.org (last visited Sep. 16, 2014). 
in the area of organ donations. However, the supply of organs can be expanded without going as far as Lifesharers does. The key is to ensure that organ donations and "exchanges" are motivated by altruism, or at least predominantly motivated by altruism.

The existing legal scheme, and the efforts to circumvent it, raise difficult questions about the underlying moral and policy goals that the law seeks to advance. As noted, philosophers identify two such basic goals: avoidance of the "commodification" of the human body, and protection of the poor. However, the notion of commodification is not clearly specified: Does it mean that one cannot gain at all from giving a kidney; that one may gain only unspecified benefits (future gratitude or loyalty); that one may gain only in-kind benefits for a third party (for example, a kidney for an altruism-linked beneficiary); or that one may gain in-kind stochastic benefits for oneself, but not money (the apparent premise of Lifesharers)? We suspect that people become increasingly uneasy about the donation of kidneys when the return benefit becomes more specific, more closely tied with the (selfish) well-being of the donor, or more fungible (with money being the extreme). The same point can be made about the poor: Perhaps they are more likely to donate their kidneys for unacceptable reasons when the return benefit is money rather than the other types of consideration. Our proposals navigate these complexities, providing a means to expand the supply of kidneys for transplantation while addressing the concerns related to commodification of the human body and protection of the poor.

III

\section{PROPOSALS}

\section{A. Altruistic Exchange Through Barter}

Under existing law, the donation of a kidney for altruistic reasons is permitted. Furthermore, kidney-for-kidney swaps are considered altruistic. Once we accept that an individual who wishes to give someone else a kidney for altruistic reasons can be allowed to swap that kidney for another kidney that is also being given for altruistic reasons (altruism on both sides), a range of additional possibilities opens.

People vary in their altruistic preferences. Some people might be willing to donate their kidneys in order to obtain a kidney for a loved one. But there are others who might have equally strong inclinations toward altruism-just not in the direction of helping someone who needs a kidney. They care about other issues: funding cancer research, for example, or improving education in Africa. These individuals may not be willing to donate their kidneys for the satisfaction of helping someone with renal disease, but might be willing to do so in return for a charitable benefit that they care about. Put another way, people who are currently just outside the realm of willing donors might choose to donate if given additional altruism-related motivation.

Our first proposal is to expand the range of lawful altruistic exchanges to 
take advantage of the existing legal fiction that altruistic exchanges are not for "valuable consideration" for purposes of NOTA. Under this proposal, a person may "barter" his kidney in return for a promise by someone else to engage in a charitable activity. Figure 4 shows this type of transaction.

Figure 4

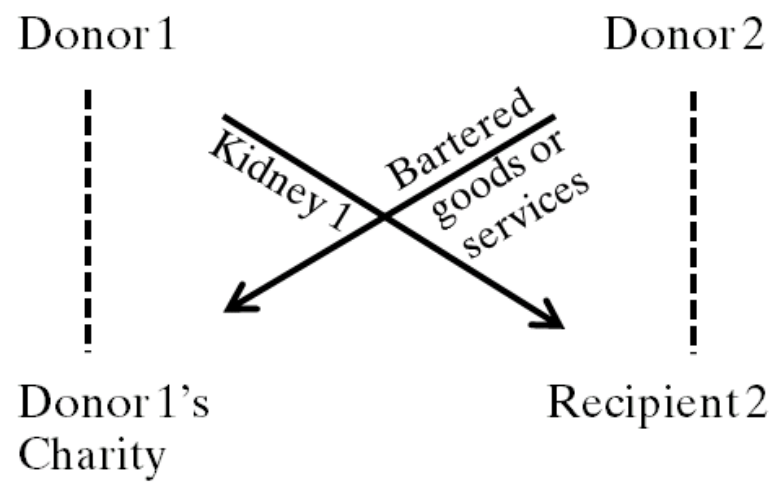

Suppose Andy is a math teacher who wants to find a kidney for his sister Alice. However, Andy's kidney is not compatible with Alice's immune system. Beth has a kidney that is compatible with Alice's immune system, but Beth does not care about Alice and only marginally cares about kidney donations in general. Instead, Beth has an altruistic preference for helping poorly educated children in developing countries: for example, by funding teachers for them. Beth herself is unable to leave the country, nor does she have any teaching experience. Under a broadened concept of altruistic exchange, Beth could agree to donate her kidney to Alice in return for Andy's promise to work for two years as a teacher in a developing country. Indeed, we would permit Beth to donate her kidney to Alice in return for a promise from Alice to engage in the charitable activity (an exchange we refer to later in the paper as one-sided altruism because although Beth is acting altruistically, Alice is not-Alice, the kidney recipient, herself benefits from the transplant); Andy's participation is not necessary unless Alice is unable or unwilling to participate. Meeting Beth's altruistic desire to provide teachers to disadvantaged children, plus any additional altruistic benefits Beth might receive from saving another person's life through the kidney donation in our example, pushes Beth across the margin so that she donates her kidney.

The key difference between this example and approved kidney exchanges is that Beth, the kidney donor, receives what we will call a "charitable benefit" (the performance of an activity that advances Beth's charitable goals) rather than another, more compatible kidney for someone she cares about (which, under our definition, is also a "charitable benefit"). This difference is a problem from a legal perspective. The Norwood Act excludes only the "human organ 
paired donation," that is, the kidney exchange, from NOTA's prohibition on the transfer of kidneys for valuable consideration. An argument could be made that a barter exchange does not run afoul of NOTA's prohibition on exchanges of kidneys for "valuable consideration" because that prohibition does not rule out altruistic exchanges; but if that interpretation were correct, it would be hard to understand why Congress felt that the Norwood Act would be necessary to permit kidney exchanges.

However, the important point for present purposes is that the moral and policy impulse behind NOTA and the Norwood Act extends straightforwardly to kidney barters. In a kidney exchange, Donor 1 gives a kidney to Recipient 2, in return for Donor 2 giving a kidney to Recipient 1 . In a kidney barter, Donor 1 gives a kidney to Recipient 2 in return for Donor 2 giving a charitable benefit to a third party. We see no morally relevant distinction between Donor 2 giving a more general charitable benefit (of which a kidney is just one instance) and giving a kidney; nor do we see a relevant moral distinction between Donor 2 giving this benefit to anonymous third parties (for example, children in developing countries) and giving this benefit to an identified Recipient 1.

Indeed, the usual reasons for being skeptical of kidney markets provide a stronger case for kidney-for-charitable-benefit exchanges (that is, barter exchanges) than for kidney exchanges. The kidney barter requires only one person-not two-to give away a kidney; thus, any type of "commodification" problem is minimized. Moreover, the kidney barter permits potentially superior charitable benefits. One might believe, for example, that helping disadvantaged children in poor countries is more morally compelling than helping an American-perhaps an elderly person who has already lived a full life and is surrounded by luxuries-who happens to have a friend or family member willing to make a kidney donation.

In practical terms, this proposal potentially expands the possible supply of kidneys (as well as other charitable donations). Under current law, people will make living donations of kidneys only out of "pure" (stranger-focused) altruism, which is exceedingly rare, or for the benefit a relative or friend. But there might be a large pool of people whose altruism takes other forms, and who might be willing to donate a kidney in order to help their favored cause. Under this proposal, those people will both be able and motivated to add their kidneys to the supply. Moreover, this proposal addresses the concern of those who argue that providing a for-profit payment to donors will cause the altruists

32. An indication of the government's likely view on such a program is the position that the Department of Justice took in a recent case involving bone marrow donations. In Flynn v. Holder, a nonprofit organization, MoreMarrowDonors.org, which was seeking to increase bone-marrow donations, proposed giving \$3000 in scholarships, housing allowances, or gifts to charities of the donor's choice. 684 F.3d 852, 856 (9th Cir. 2012). Both parties agreed that the payments constituted valuable consideration under NOTA. $I d$. at 858.The plaintiffs contended that NOTA did not apply because bone marrow extracted via the newly invented process of apheresis constituted a form of blood, which had specifically been excluded from the ambit of NOTA. Id. at 858-59. The Ninth Circuit agreed with the plaintiffs. Id. at 865 . 
to exit the market, presumably because the act of donation no longer carries with it a "pure" signal of altruism. ${ }^{33}$ Because all exchanges under this proposal are motivated by altruism, those who desire to donate a kidney directly to help another or in return for another kidney should not react negatively to the prospect that others are donating their kidneys in return for some unrelated, but nonetheless altruistic, benefit.

An "altruistic exchange" might sound like an oxymoron, but it is not. As Figure 4 shows, an exchange is compatible with altruism. The donor's motivation for making a kidney donation must be to provide a benefit to a third party, not to the donor herself. This feature is also present in the kidney exchange; the only addition is the idea that a donor may donate her kidney in order to benefit a chosen recipient by obtaining for him something other than a kidney.

We can think of six objections to barter altruistic exchanges. First, one might wonder whether the donation of a kidney is such a large gift that it would be hard to find altruistic substitutes for it. The Beth in our hypothetical might simply not exist; the real-life Beths of the world might not be willing to donate their kidneys in exchange for the Andys teaching in Thailand. At the margin, though, there are surely at least some types of altruistic exchanges that would help motivate additional donors. ${ }^{34}$ Although some will donate their kidneys purely for the altruistic benefit that comes from the donation, there might be others for whom helping a single other person is not sufficient motivation for making a donation, but helping many people or advancing a cause is. The question is an important one, though, and is addressed below.

Second, there is the possibility of sham altruism. For example, Beth might agree to donate her kidney because she is in dire financial straits. In return, she asks that the counterparty in the transaction agree to "donate" his labor for the next two years working at XYZ charity (but Beth knows that XYZ charity will pass money under the table to her). However, sham altruism is not unique to the altruistic exchange proposal. In the United States, a screening mechanism already exists to identify charities that are deemed worthwhile enough to receive tax deduction status by the Internal Revenue Service under section 501(c)(3) of the Internal Revenue Code. ${ }^{36}$ For this proposal, transfers of labor can be treated as altruistic if the labor is donated to a section 501(c)(3) charitable organization.

33. See SATZ, supra note 7, at 193 (noting that "intrinsic motivation is partially destroyed when price incentives are introduced"); Richard A. Epstein, The Human and Economic Dimensions of Altruism: The Case of Organ Transplantation, 37 J. LEGAL STUD. 459, 475 (2008). For-profit kidney sales might also give sellers an incentive to sell kidneys that the sellers know to be diseased; presumably altruists would not have the same incentive to donate a kidney known to be with disease. SATZ, supra note 7, at 192; see also Maurice McGregor, Pragmatic Altruism, 160 CAN. MED. Ass'N J. 91 (1999) (discussing the same concern).

34. See Epstein, supra note 33, at 470 (noting that not all altruists are willing to sacrifice equally).

35. See infra, p. 297.

36. I.R.C. § 501(c)(3) (2006). 
Third, related to the sham-altruism critique, is the argument that money is fungible. If a potential kidney donor already planned on giving $\$ 2000$ a year for life to a particular charity, then the donor may use the charitable dollars obtained from a kidney exchange under this proposal (say $\$ 100,000$ ) to satisfy the donor's preference to give to the charity and shift the $\$ 2000$ the donor otherwise would have given directly to the charity to use on purely personal goods and services. Nonetheless, not everyone will have the necessary cash to make $\$ 100,000$ of charitable contributions in his or her lifetime absent a kidney donation. For people in this category who have a preference to donate $\$ 100,000$ but lack the financial wherewithal, the altruism exchange provides a means of satisfying this preference. On the flip side, those with the cash to make a $\$ 100,000$ donation even without a kidney donation are unlikely to be the type of persons who are vulnerable to financial coercion to make a kidney donation.

Fourth, matching different altruistic impulses directly through barter is significantly more difficult than matching donors and recipients in a kidney-forkidney gift exchange. A universally agreed-upon rate of exchange exists for kidney-for-kidney exchanges: one kidney for one kidney. But how is Andy in our example supposed to find out that Beth is willing to exchange her kidney for two years of teaching services in a developing country? Solutions are possible. The MatchingDonors website enables potential donors and recipients to find one another quickly by doing searches over the Internet. ${ }^{37}$ With a small modification, websites such as MatchingDonors could allow those interested in donating a kidney in return for some other altruistic donation to post whatever kind of donation they seek. Those in need of a kidney (or friends and family of the potential recipient) could then search among desired altruistic donations to find a suitable match.

As with any barter market, altruistic gift exchanges also face the problem of comparability. Because there is no common medium of exchange, even if people eventually develop agreed-upon exchange ratios for certain altruistic exchanges (say one kidney for two years of teaching, or for one year of building homes for the homeless, or for three bone-marrow transplants), anyone seeking to obtain a kidney through an altruistic exchange must navigate all these different exchange ratios. Moreover, what if $\mathrm{X}$ is willing to donate three bonemarrow transplants but no matching potential kidney donor wants this form of altruism in return? Instead, Y, a matching potential donor, wants someone to spend a year building homes for the homeless. $X$ must then find and negotiate with $\mathrm{Z}$, a person who cares greatly about bone marrow transplants and who is willing to work for one year building homes, to craft a three-way trade that will ultimately induce $\mathrm{Y}$ to donate her kidney. The information and transaction costs associated with such a three-way altruistic transaction could prove

37. See MATChINGDonORs, http://www.matchingdonors.com/life/index.cfm? (last visited Nov. 13, 2012); see also Epstein, supra note 33, at 490-91 (discussing MatchingDonors and observing that "[b]y narrowing the potential matches for any prospective donor and allowing easy interchange, it increases the odds of a directed donation, with a positive impact on supply"). 
considerable.

Fifth, when the altruistic exchange is not simultaneous, there is the problem of default. Andy, for example, might simply renege on his promise to teach math for two years in a developing country after his sister Alice receives a kidney from Beth. Alternatively, if Beth promises to give up her kidney only after Andy teaches for two years, Beth might renege on this promise and keep her kidney once Andy completes his teaching work. Although treating an expanded altruistic exchange as not for "valuable consideration" will result in the exchange meeting the restrictions of NOTA, it also undermines contract enforcement because a promise can be enforced only if it is made in return for consideration. As with kidney-for-kidney gift exchanges, an expanded definition of gift exchange to include kidney barter faces the problem of enforcement.

Lastly, providing extra altruistic incentives that aim to induce more people to donate kidneys, such as Beth in our example, might change people's behavior in potentially objectionable ways. Carl, for example, might initially plan to donate his kidney to benefit a stranger on the United Network for Organ Sharing (UNOS) waiting list due to his altruistic preferences. The possibility of altruistic barter might cause Carl to drop this plan and instead donate his kidney to someone else. Carl might choose to donate his kidney instead to a particular recipient in California who has a friend willing to spend a year taking care of redwood trees in Marin County, a topic of particular importance for Carl. A critic might argue that this proposal will therefore undermine the priority order established within UNOS. ${ }^{38}$ However, that priority order is already undermined by kidney donations to friends and family: The increase in supply justifies the marginal interference with the UNOS order (which itself is open to criticism). Our proposal would further expand the supply of kidneys, while having the additional benefit of expanding the supply of other charitable goods and activities as well.

\section{B. Altruistic Exchange Through Money}

Our second proposal is to permit altruistic exchange involving monetary donations rather than in-kind goods (like kidneys) or services (like teaching). Under this proposal, any person who donates a kidney would receive a sum of money that the person is required to use for charitable uses. The donor is permitted to donate the payment immediately or in the future to any charity. The only difference between this proposal and the first proposal is that the donor receives money earmarked to an as-yet unidentified charitable purpose rather than the immediate delivery of an identified charitable good or service. ${ }^{39}$

38. Cf. Sheldon Zink, Stacey Wertlieb, John Catalano \& Victor Marwin, Examining the Potential Exploitation of UNOS Policies, 5 AM. J. BioETHICS 6 (2005) (describing how the UNOS system, designed to provide for fair and equal allocation of organs, has the potential to be exploited so that some receive an unfair advantage).

39. See Sally Satel \& Mark J. Perry, More Kidney Donors Are Needed to Meet a Rising Demand, 
Figure 5 shows the transaction.

Figure 5

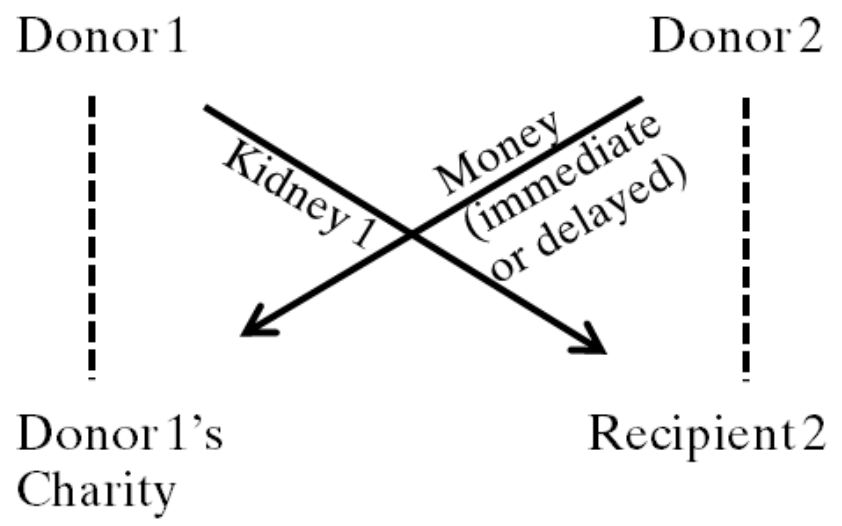

Suppose that Beth has a strong preference to fund the arts. Beth, however, lacks the financial means to make good on her altruistic preference to the extent she desires. This proposal would allow Beth to donate her kidney in return for a lump-sum payment to a particular art establishment such as a museum (so long as the recipient meets the Internal Revenue Code section 501(c)(3) requirements as a charity). ${ }^{40}$ One could also imagine postmortem donations, in which Beth could agree to donate her kidney upon her death in return for a donation of money in Beth's name to charities of Beth's choosing.

Allowing money as a medium of exchange also allows those with a desire to spread altruistic donations over time to do so, with money acting as a store of artistic value. Someone willing to donate a kidney in return for satisfying her altruistic preferences in another area might wish to store the value of the altruism over time or partition the altruism over different causes. Money allows the person donating the kidney to store the value of the altruism (in the form of money) until she desires to engage in altruism and divide the money across several different charitable causes. Beth, for example, might decide to give the

WASH. POST (Mar. 7, 2010), http://www.washingtonpost.com/wp-dyn/content/article/2010/03/05/ AR2010030502971.html (making a proposal about receiving a future benefit). This proposal is also analogous to the proposal analyzed by the Ninth Circuit in the bone-marrow context in Flynn $v$. Holder, in which the organization MoreMarrowDonors.org would donate $\$ 3000$ to a nonprofit or charity on behalf of the donor. 684 F.3d 852 (9th Cir. 2012).

40. A reason to limit the recipients of donated money is the need to block transactions that might provide a hidden benefit to the kidney donor. For example, one might worry that a donor might donate her kidney in return for money that goes to her child, claiming that because she has an altruistic relationship with her child, she is entitled to donate in return for a charitable benefit for her child. Some people might argue that this type of transaction would harm poor people who care about their children, encouraging them to sell kidneys in order to finance their children's education. One might respond that this type of transaction does not seem like exploitation of the poor: Money for a child's education might be money well spent. Nonetheless, by requiring that only qualified 501(c)(3) charities would be permitted to receive money payments in return for kidney donations, we foreclose this type of transaction whether or not it is deemed objectionable. 
money she receives for her kidney over the next ten years to different art programs in the San Francisco public school system depending on the performance of the different schools. Beth might also wish to use the money obtained from donating her kidney to "pay" for the donation of another kidney in the future. Allowing kidney donations in return for charity-restricted money thus allows someone like Beth to store the value of her kidney donation, allowing her to provide for a loved one in need of a kidney in the distant future when her own kidney might no longer be a viable candidate for transplantation.

The use of money as a means of payment, even for altruistic exchanges, poses a number of challenges. First, if barter altruism exchanges run afoul of the law, as suggested above, then monetary altruism exchanges will as well. Thus, the law would need to be amended in order to permit monetary (as well as barter) altruism exchanges involving kidneys.

Second, the use of money as a medium of exchange might be viewed as qualitatively different from barter because money will require participants in altruistic exchanges to put a price on a human body part, the kidney. Those worried about the commodification of the human body might object to having a price set for a kidney (say $\$ 50,000$ ) even if the money must be used for charitable purposes. That said, any altruistic exchange for kidneys implicitly requires a price (one kidney for one kidney; or in the case of our altruistic barter exchange example above, one kidney for two years teaching math in a developing country). The price is not denominated in money terms but instead in terms of other body parts, goods, or labor. But there does not seem to be much difference between setting a price in dollar terms and setting a price based directly on body parts, goods, or labor. A price is just a shorthand reference to all the other possible things that one can buy using the purchasing power that one receives in return for a sale. Rather than exchanging a kidney for a kidney, or a kidney for support for art museums, one is exchanging a kidney for charity-limited purchasing power that would end up financing a kidney, an art museum, or any other approved charitable use. It is hard to see why the third activity is immoral if the first two are acceptable.

Another response to critics of cash payments is to not set the price of a kidney based on market forces, but instead based on some objective metric that reflects the cost savings from a kidney transplant. Some authorities estimate that a kidney transplant will result in over $\$ 50,000$ a year in saved dialysis costs for each kidney recipient. ${ }^{41}$ The price for a charitable donation of a kidney could therefore be set on the basis of this cost savings: for example, $\$ 100,000$ if two years of dialysis are avoided. ${ }^{42}$ The price, therefore, would not represent an attempt to quantify the inherent value of a kidney, and by extension a human being, but instead would simply be based on the amount of cost savings from a

41. See Satel \& Perry, supra note 39; Tuller, supra note 4.

42. See Satel \& Perry, supra note 39; Carmen Chai, Kidney Transplants Could Save Health-Care System Millions, CANADA.COM (Jan. 21, 2012), http://www.canada.com/health/Kidney+transplants+ could+save+health+care+system+millions+Report/4144445/story.html. 
transplant. Taking into account cost savings has one additional benefit. Rather than a simple one-kidney-to-one-kidney ratio in today's gift exchanges, one could imagine a price set based on the cost savings of a particular kidney. Therefore, a kidney from a younger, healthier donor would receive a higher price than a kidney from an older or deceased donor simply because the kidney from the younger, healthier donor will generally last longer and result in greater dialysis cost savings. The younger, healthier donor would thus have a greater incentive to donate to obtain a larger payout that the donor can then use to provide greater funding to the charities of her choice. Although market forces will of course determine the price of dialysis treatments, and therefore the cost savings, these market forces will not be based directly on the value of a human life or organ, but will instead be based on the relative demand and supply of dialysis treatments. A technological improvement to dialysis machines, for example, will have a market impact on the cost of dialysis treatments that does not require any market valuation of a human life or organ.

In sum, the second proposal extends the idea that altruistically motivated exchanges do not offend moral principles by encompassing the use of monetary payment as a medium of exchange. Nonetheless, as with a bartered altruistic exchange, monetary altruistic exchanges face the problem of default. What happens when Beth donates her kidney and then the counterparty reneges on his promise to give Beth's favorite charity a monetary payment? In addition, Beth must have a place to store her money that will also ensure that she actually uses the money only for altruistic causes. In such a situation, the presence of institutions that can intermediate in altruistic exchanges provides a solution. This is the subject of the third proposal.

\section{Intermediaries and Enforcement Mechanisms}

The third proposal addresses the role of intermediaries both in ensuring compliance with NOTA and in enabling a mechanism for enforcement of altruistic exchanges, focusing on specific charities as altruistic-exchange intermediaries, or "altruism exchanges." Consider a charity, for example the Red Cross, that announces that it will henceforth accept kidney donations (on behalf of recipients) and in return will allocate funds to charities designated by the donor up to the amount thought to be the value of the kidney donation (for example, the medical costs that are saved, which might be as much as $\$ 100,000$ ). Under this proposal, a person who wants to help another in need of a kidney ${ }^{43}$ would be permitted to "donate" a cash payment to the charity in return for a promise from the charity to find a kidney for the beneficiary. The charity will match the donor's kidney with a specific person donating cash-choosing the recipient of the kidney from the pool of existing cash donor-recipient pairs based on tissue compatibility and, in case of equal tissue compatibility, the time order with which the cash donor transferred money into the altruism exchange.

43. And also potentially the recipient himself; but this raises additional issues that are discussed in Part III.D, infra at 302-07. 
The charity will then use the monetary donations to finance the kidney donor's charitable agenda up to $\$ 100,000$. Figure 6 shows how the altruism exchange would work (where, for the purpose of example, we depict Recipient 2 as the recipient whose donor made a payment to the altruism exchange before any of the other donors, assuming tissue compatibility).

\section{Figure 6}

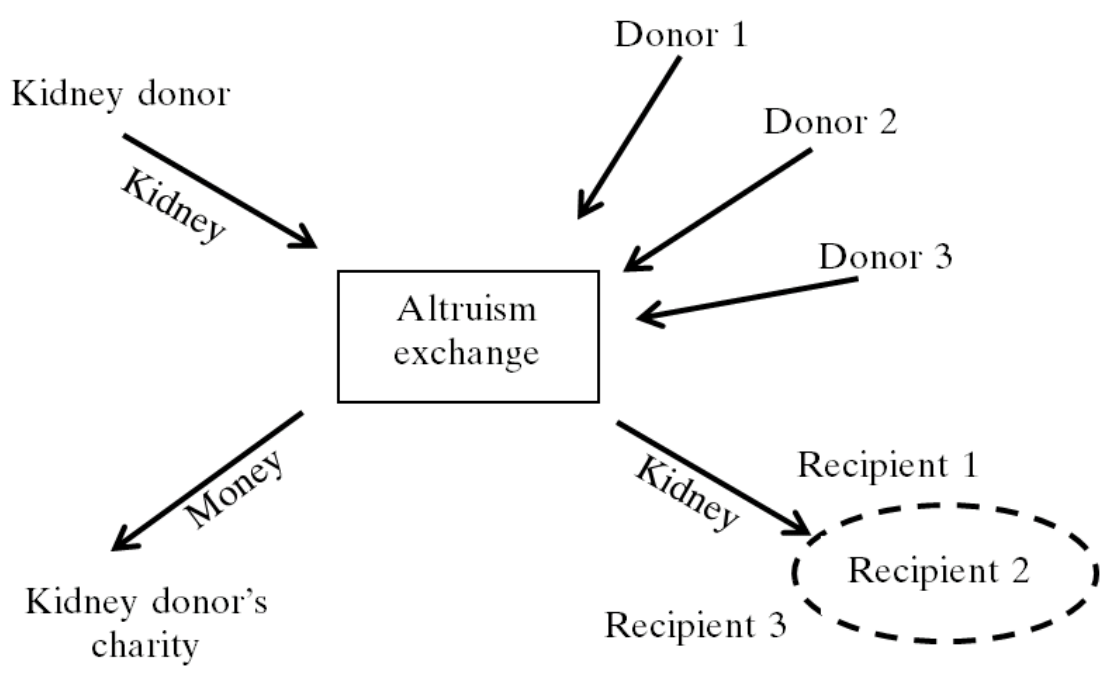

The principal advantage of the altruism exchange is that it introduces liquidity. Currently, it is difficult and expensive to arrange kidney exchanges and kidney chains. When the donor and recipient do not match, officials must seek out a matching pair or construct a chain, and this involves laborious information gathering. All donors and recipients must wait until the pair or chain is constructed, and then operations must be performed simultaneously (or near simultaneously). By contrast, the altruism exchange would enable donors to make kidney donations whenever they want. Thus, a continuous supply of kidneys would enter the pipeline. Meanwhile, their designated recipients would receive kidneys based on tissue compatibility and the order in which donors make donations. The kidney supply would be further expanded as a result of the donations from altruists who seek monetary benefits for other beneficiaries.

The altruism exchange would also reduce counterparty risk. Consider (1) the donor of a kidney (Donor K), (2) the counterparty donor of money (Donor M), (3) the recipient of the kidney (as selected by the counterparty) (Recipient $\mathrm{K}$ ), and (4) the recipient charity of the money (as selected by the donor of the kidney) (Recipient M). The altruism exchange would handle the transfer of money from Donor $M$ to Recipient $M$ and the transfer of the kidney from Donor K to Recipient K. Because each party deals directly only with the altruism exchange, each party would look to the exchange for performance. Donor $\mathrm{M}$ would move first by paying the altruism exchange. Donor K would 
next donate his kidney to Recipient $\mathrm{K}$. If he does so, then the altruism exchange would pay Recipient M. If Donor K reneges on his promise, then the altruism exchange would put Recipient $\mathrm{K}$ at the top of its list for kidney donations and allocate the next compatible kidney to her. Donor M's money would be allocated to the next kidney donor's chosen beneficiary rather than to Recipient M. If enough people are involved in the altruism exchange, wait times would be negligible; Donor M would not even know that Donor K had reneged.

The altruism exchange could handle storing the value of the money for Donor K until Donor K selects the specific charity (Recipient M, which could include a future recipient in need of a kidney transplant) to which the money should be transferred. The exchange could also screen charities, going beyond the 501(c)(3) list of charitable entities. Assuming there was concern that the current designation of charitable entities was too broad or loose, exchange administrators could reduce the number of charities from the 501(c)(3) initial list using criteria such as years in operation, size of charity, purpose, and so on.

The altruism exchange could also act as a receiver of general charitable donations aimed at increasing the number of available kidneys. The current system, by restricting kidney exchanges to those willing to make big altruistic contributions, fails to capture lesser altruistic inclinations. Suppose a number of people wish to help someone in need of a kidney but do not wish to donate their own kidneys. These people could each donate a small amount of money that the exchange could then aggregate into a larger sum that could be used to pay for the charitable benefit desired by the person who donates a kidney. Thus, the altruism exchange would allow those with some preference to help those in need of a kidney-but not a strong enough preference to donate their own kidney-to also contribute.

\section{Do the Commodification and Poverty Objections Apply to Altruism Exchanges?}

The major focus of the commodification concern-the sale of body parts in return for cash consideration-is absent in the altruism exchange. ${ }^{44}$ Nonetheless, those who worry about commodification might object to the altruism exchange for two reasons. First, the altruism exchange will need to identify a "price" at which a monetary donation to a designated charity will entitle a donor's beneficiary to receive a kidney. In this respect, the altruism exchange raises the same issues as monetary transfers discussed above. Moving from a kidney-forkidney exchange to an exchange of a kidney for some other charitable good, service, or donation will require parties in such an exchange to consider an exchange ratio. Some will argue that the very act of considering an exchange ratio results in commodification. Even if this critique is valid, the kidney-forkidney exchange is equally susceptible to the critique. In the voluntary kidney

44. Because the donor of a kidney receives no direct cash payment, the commodification concern is similarly absent from our proposals for barter and monetary altruistic exchanges that occur outside of a formal altruism exchange. 
exchanges permitted today, potential donor and recipient pairs do not blindly accept the proposition that one kidney is always worth one kidney without recognizing the need to assess the value of a particular kidney. Donors and recipient pairs surely consider the age and health of kidney donors and their kidneys. A kidney from a seventy-year-old donor is not considered as valuable as a kidney from a twenty-year-old donor. Human body parts are already assessed and valued in today's voluntary paired kidney-exchange regime. Therefore, this form of commodification argument is not a reason to distinguish the altruism exchange proposal from existing paired-kidney exchanges.

Second, one might worry that the altruism exchange will "crowd out" purely altruistic donations of kidneys, resulting in a reduced supply. ${ }^{45}$ A person who would otherwise have been willing to make an anonymous donation of a kidney might now, under the new system, refrain from making such a donation unless her designated charity is paid. However, on balance, supply should increase. People not otherwise inclined to donate kidneys will do so because the altruism exchange both allows them to raise money for charity and makes it more likely that they can ensure that an altruistic beneficiary will receive a kidney from someone else.

Some might also worry that crowding out might occur if the perception of those who donate changes. If those who contribute a kidney for nothing in return are viewed as more altruistic than those who contribute a kidney in return for a charitable contribution, then those who care about the perception of their donation might choose not to donate-for they are indistinguishable from other donors who donate in return for a charitable contribution. However, the premise of this argument is flawed. People who donate their kidneys in return for a charitable contribution are no less altruistic than people who donate their kidneys in return for "nothing." The only difference is that the altruism of the first group of people is directed toward other people (for example, malnourished children in Sudan), whereas the altruism of the second group of people is directed toward the kidney recipients. In any event, if this were a problem, the altruism exchange could provide public certification that donors received "nothing" and were heroic.

Another crowding-out argument is that at least some living recipients of a kidney donation may shift their future activity toward more charitable work out of gratitude and other shifts in preferences due to the donation. If the same living recipients have to pay for their kidneys through the altruism exchange, they might not feel as much gratitude. Although this effect is possible, the overall impact is unlikely to be significant. First, skill and expertise matter in the value of charitable activity. Directing money from the altruism exchange to a charitable organization dedicated to particular charitable causes will likely improve welfare more than the activities of any particular living recipient with no prior experience with the specific charity. Second, under the current regime,

45. SANDEL, supra note 7, at 123-25 (making this objection to kidney markets). 
not every living recipient shifts his or her preferences toward engaging in greater charitable work, whereas with an altruism exchange in place, every living recipient would pay significant sums-through the exchange-to fund charitable activities. Third, if recipients of charity change their behavior out of gratitude in a way that is positive for society, this will be just as true for those who receive (non-kidney) charitable benefits through an altruism exchange as those who receive kidneys. The aggregate amount of gratitude in the world will not decline; it should increase if the altruism exchange increases the amount of charity, which is likely.

We turn now to the poverty objection to kidney markets and examine whether it can be made against altruism exchanges as well. ${ }^{46}$ The protection of the poor from exploitation appears to be a key concern underlying many of the objections to markets in organs (even highly regulated ones). The key characteristic of the three proposals made here is the requirement that the donor of a kidney act for altruistic reasons-whether through barter exchange for an altruistic act on the part of a benefactor of the kidney recipient or through cash payment by the benefactor, either to the charitable cause of the donor's choosing, or to an exchange to be used in a manner the donor chooses. This minimizes the risk that the poor will be subject to pressure or exploitation.

There are several reasons for this. First, the poor are vulnerable to financial pressure to generate money to eat, find shelter, and so on. ${ }^{47}$ In a for-profit market, the donor might consider selling a kidney to meet these often shortterm needs and, in doing so, incur greater long-term harm. ${ }^{48}$ Critics of kidney markets cite studies that show that the impoverished who donate kidneys often find themselves with "social, psychological, medical, employment and living problems" after the sale of a kidney. ${ }^{49}$ The poor might also be more vulnerable to others who, although purportedly acting on their behalf, might instead exploit their relationship. ${ }^{50}$ Coercive familial relationships might force the weaker family members into donating their kidneys in return for money that goes to the stronger family members. ${ }^{51}$

46. Because the donor of a kidney receives no direct cash payment, the poverty objection is similarly absent from our proposals for barter and monetary altruistic exchanges that occur outside of a formal altruism exchange.

47. See, e.g., SATZ, supra note 7, at 195 (citing "vulnerability" as one factor that might lead to "noxious" markets and writing that "[m]any people object to organ markets precisely because they believe that these markets would allow others to exploit the desperation of the poor").

48. Satz views the individual harm to a kidney donor as particularly troublesome for kidneys donated through a competitive for-profit market. See id. at 204.

49. See Joseph Hall, Opening Up The Market For Organs: Support Grows for Selling Body Parts, Donors for Profit Don't Really Benefit, TORONTO STAR, Nov. 29, 2002, at F06 (quoting Nancy ScheperHughes).

50. Satz refers to these third parties as "weak agents." SATZ, supra note 7, at 196.

51. See id. (reporting on the findings of a study of kidney sellers in India, Satz writes that "The most common explanation offered by wives as to why they and not their husbands sold their organs were that the husbands were the family's income source ( 30 percent) or were ill ( 28 percent). Of course ... most of the interviews of women were conducted in the presence of their husbands or other family members, so they may have been reluctant to admit to being pressured to donate.") 
The proposals articulated here do not give the poor any direct payment for a kidney. Without the possibility of a payment, financial need will not lead the poor to participate disproportionately as donors or face pressure from third parties seeking to profit financially. ${ }^{52}$ There will inevitably be the danger of sham charities, but the policing of entities given charitable status can be enhanced if the Internal Revenue Code's definition of charities under section 501(c)(3) is considered inadequate. The possibility of coercion remains. It is always possible that a potential recipient will coerce a poor person (perhaps a relative) to make a kidney donation to him. This is already possible under the current system; the only question is whether the broader range of options made available by these proposals will increase the risk of coercion. This is doubtful.

Second, some object to the sale of kidneys because they believe that all people should receive basic necessities as a matter of right. ${ }^{53}$ If a poor person must sell a kidney in order to obtain basic necessities, then his rights are being violated. This reasoning is questionable. Although it would be better if the state were to ensure that this person enjoyed basic necessities, in a second-best world in which he does not, depriving him the ability of obtaining them will make him worse off, not better off. Plus, even if this argument is accepted, a poor person who lacks basic necessities is unlikely to give away his kidney for nothing in return. Thus, our proposal should not raise objections in this vein.

Third, a person's financial status might also bear on that person's sophistication and access to information. ${ }^{54}$ For purposes of addressing this argument, assume that poor people frequently make worse financial decisions than other people do. Thus, the poor will make bad decisions when comparing the benefit from selling a kidney (the monetary payment) with the cost of this act (in the form of short-term health risks due to the surgery and long-term risks due to the lack of one kidney). Despite the fear of bad decision-making, altruistic kidney donations are lawful today. The lack of financial incentives reduces the possibility that the poor will make bad decisions regarding a kidney transplant. Although bad decisions are possible even for those making an altruistic donation, the likelihood of a bad decision is greater when the donor faces short-term financial pressure. Short-term financial pressure on the poor might reduce the time the poor spend considering a decision to donate a kidney. All of that said, regulatory responses exist to address the problem of a lack of information or sophistication regarding transplant decisions-including education and the imposition of waiting periods.

Fourth, it is also possible that the wealthy will have a greater ability to make

52. See id. at 198 ("By contrast, a procurement system that relies on donation is much more likely to have suppliers that come from all classes of people.").

53. See id. at 6 (observing that "[n]ineteenth-century social liberals such as T. H. Marshall argued that some specific goods, such as education, access to employment, health care, and votes, are necessary if citizens are to be equals and so should be guaranteed as a right").

54. See id. at 196 ("The fact that most organ sellers would not recommend the practice suggests that potential sellers would be unlikely to sell a kidney if they were better informed about the outcomes of their sale."). 
the required charitable payment to acquire a kidney once money is introduced as a medium of altruistic exchange. Thus, poorer recipients might be put to a disadvantage under this proposal. But this problem can be surmounted. Insurance companies or the government save the cost of dialysis treatments rendered unnecessary by a successful kidney transplant, and can use this money to make the charitable payment on behalf of poor patients. ${ }^{55}$ Moreover, groups of recipients might collectively benefit from obtaining a kidney through an altruism exchange, allowing the group to pool their resources to make the payment, diminishing the amount of money required from any one kidney recipient. These proposals could also complement existing NEAD chains. One problem with NEAD chains is finding an initial altruistic donor to start the chain and then fixing breaks in the chain if a particular donor-recipient pair reneges. Suppose that, on average, one in every twenty links in a NEAD chain breaks due to a particular recipient-donor pair reneging on their promise to donate down the chain. Participants in a chain can each contribute a fraction of the monetary charitable-exchange payment amount for a kidney to fill the gap caused by the break (in our example, one-twentieth of the cost of a kidney). The NEAD-chain organizers can then use this money to obtain the initial kidney as well as keep some money in reserve for the possibility of future breaks in the chain.

Fifth, the existence of a market for kidneys might affect how people interact with one another, and in particular, how the rest of society views those who donate their kidneys. One view is that markets become "noxious" when they undermine equality and thus the underpinnings of a democratic society. ${ }^{56}$ To the extent the poor disproportionately donate kidneys for cash payments, this might reinforce the view that the poor are simply "spare parts" for the wealthy, further embedding unequal attitudes about the poor and wealthy in society. A for-profit market for kidneys might also have collateral effects on other markets. The possibility exists that once kidneys are viewed as a financial commodity, lenders might seek to use kidneys as collateral for loans. ${ }^{57}$ The poor who would not consider selling their kidneys will thus be put at a disadvantage in the market for loans-placing even more financial pressure on the poor to sell their kidneys. ${ }^{58}$ Other opponents of for-profit kidney markets argue that if the United States allows a for-profit market then other countries will followwith less regulated and protected markets. Even if the United States provides safe and highly transparent for-profit kidney markets, donors in other countries might not benefit from these protections, leading to even greater exploitation of the poor and the unsophisticated than in today's black markets. ${ }^{59}$

55. See id. at 199 ("Through subsidy and insurance the government could seek to make the demand for kidneys independent of the wealth of the buyer.").

56. See id. at $91-112$.

57. See id. at 200-01.

58. See id.

59. See Jessica Pauline Ogilvie, The Consequences of a Donor Kidney Market, L.A. TIMES, Mar. 28, 2011, at E1 (reporting the views of Dr. Francis Delmonico, director of renal transplantation at 
An altruism-exchange market would not result in these negative effects. Those who donate altruistically will not be viewed as less than equal by others in society, and indeed might be celebrated by others for their self-sacrifice. Once profit motives are removed from the market, collateral effects on the loan market, as well as on other countries, are also diminished.

A final note to consider is that if these proposals are successful in increasing the supply of kidneys, this increase in supply will help reduce the demand for kidneys in the black market. The reduction in demand will likely reduce the market-clearing price in the black market, leading to fewer poor people making the choice to sell their kidneys, as well as diminishing the possibility of coercion on the weaker segments of the population to donate their kidneys. Introducing legitimate charitable institutions as altruism exchanges also will eliminate the negative side effects from the participation of criminal organizations in the black market. At a minimum, legitimate charitable institutions will ensure that those who donate their kidneys can expect that the money received for their donations will go to the charitable cause of the donor's choosing.

\section{E. Exchanges With One-Sided Altruism}

So far cases of two-sided altruism have been considered. Donor 1 donates a kidney (or earmarked cash or other charitable benefit) to Recipient 2 . Recipient 2 is the altruistic beneficiary of Donor 2. Donor 2 donates a kidney (or other charitable benefit) to Recipient 1 , who is the altruistic beneficiary of Donor 1 . These donations could take place through an altruism exchange, but the important point for present purposes is that the original donor acts altruistically and the ultimate recipient benefits from the altruism of another person.

Consider a variation, referred to here as one-sided altruism. There are two versions. In the first version, "sell-side altruism," Donor 1 is linked to Recipient 1 by altruism, but Donor 2 acts for himself. For example, Donor 1 donates a kidney to Donor 2, and Donor 2 reciprocates by donating, say, bone marrow, to Recipient 1 . In the broader case, Donor 1 donates a kidney to Donor 2, and Donor 2 provides money to a charity chosen by Donor 1 , or to an altruism exchange that directs the money to a charity chosen by Donor 1 . The transaction is shown in Figure 7.

Massachusetts General Hospital). 
Figure 7

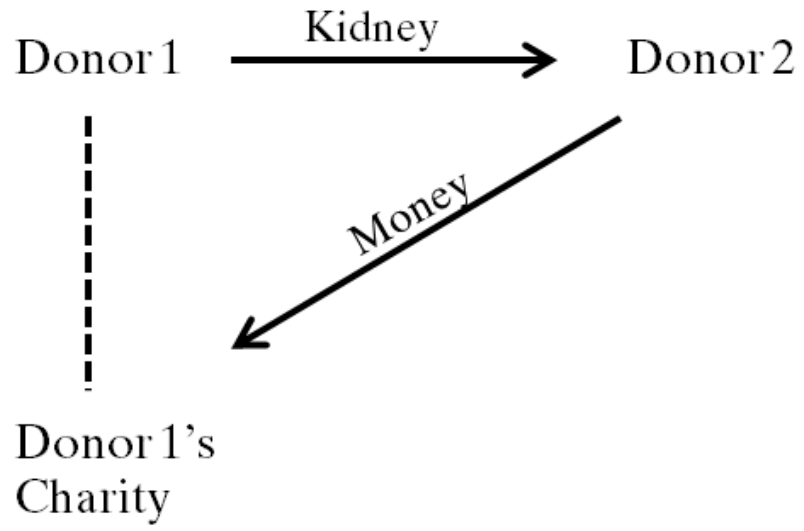

This is one-sided altruism. Donor 1 is motivated by altruism; Donor 2 is not motivated by altruism, but by self-interest, whether he donates bone marrow or cash to the third party. Thus, Donor 2 is effectively buying a kidney, but Donor 1 is not selling his kidney: He is donating his kidney.

Does a one-sided altruistic transfer offend moral sensibilities? The answer depends on one's theory for banning the commodification of kidneys. If the reason is that poor people might be coerced or exploited, then transactions in which the kidney donor receives only a charitable benefit is not objectionable: Poor people will not, except in unusual cases, voluntarily donate their kidneys when someone else receives the cash or other charitable benefit. This system, therefore, provides no greater danger to the poor than two-sided altruism.

The next objection is that people become a bundle of "spare parts"-that human dignity is undermined. Here, again, the donor of the kidney does not act any differently from the way the donor acts in the two-sided altruistic exchange. Accordingly, if the commodification concern is focused on the motivations and behavior of the donor, then one-sided altruism is no more objectionable than two-sided altruism. On the other hand, if the focus is on the recipient of the kidney (Donor 2), it is true that he gave money for it, although the money is to be used for altruistic purposes, which is not the case when one buys spare parts from an automobile supply store. People will react differently to this scenario; at a minimum, it is not as vulnerable to the commodification criticism as a regular sale would be.

By contrast, consider the second version of one-sided altruism, referred to as buy-side altruism. Here, Donor 1 accepts money from Donor 2 and gives his kidney to Recipient 2, who is linked to Donor 2 by altruism. Figure 8 shows the transaction. 
Figure 8

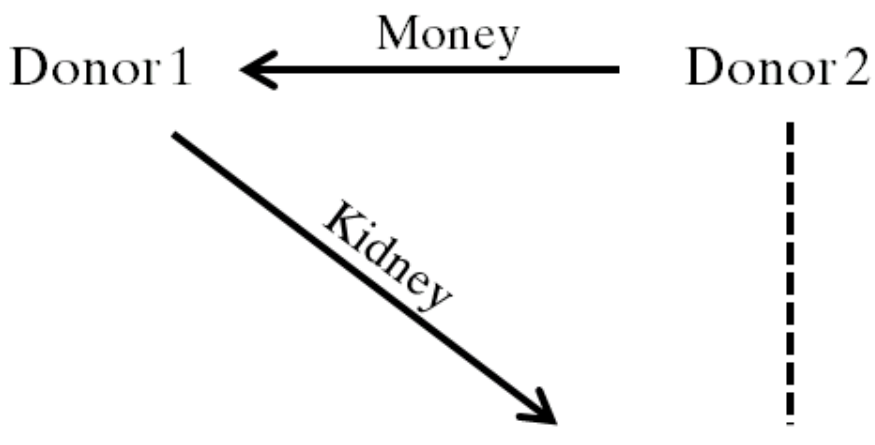

Recipient 2

In this transaction, Donor 1 is simply a kidney seller who obtains a financial gain from the sale, whereas Donor 2 buys on behalf of another person. Both the poverty and commodification worries come into play here. If Donor 1 is poor, then he will be tempted to sell his kidney in return for money. At bottom, this straightforward sale of a kidney, even if to an altruistic buyer, might create a market in kidneys that critics of commodification will find objectionable.

\section{F. How Many People Are Likely to Participate?}

Will any of these proposals result in an increase in the supply of kidneys? Who will be willing to exchange a kidney in return for the right to allocate someone else's money to a charitable beneficiary? To answer, consider two separate cases that we have so far considered together: recipients that are charitable organizations and recipients who are children (or other relatives or close friends).

\section{Charities}

Charitable giving is a significant phenomenon in the United States. In 2011, 117 million households collectively donated over $\$ 200$ billion to charity. ${ }^{60}$ Some individuals make enormous charitable contributions. For example, in 2008 the entrepreneur Hansjörg Wyss donated \$125 million to underwrite a new biological engineering institute at Harvard University. ${ }^{61}$ A group of billionaires, including Bill Gates and Warren Buffett, have promised to contribute half their wealth to charities. ${ }^{62}$ Whatever the motivation-pure altruism, reputation, or

60. See Giving USA \& The Center on Philanthropy at Indiana University, The ANNUAL REPORT ON PHILANTHROPY FOR THE YEAR 2011 EXECUTIVE SUMMARY 4 (2012), available at http://www.etsu.edu/125/documents/GIVING\%20USA\%202012.pdf.

61. Erin Zlomek, Harvard Gets $\$ 125$ Million Gift From One of Its Own, BLOOMBERG BUSINESSWEEK (May 21, 2013), http://www.businessweek.com/articles/2013-05-21/harvard-gets-125million-gift-from-one-of-its-own.

62. See, e.g., Warren Buffett, Bill Gates' 'Giving Pledge' Gets 11 More Billionaires To Pledge Half Of Wealth, HUFFPOST IMPACT (Sept. 19, 2012), http://www.huffingtonpost.com/2012/09/19/warren- 
something else-the impulse to give to charitable organizations is strong and widespread.

The charitable impulse extends beyond donations of money. People volunteer in soup kitchens, build houses for the homeless, and provide other services. Lawyers and doctors frequently offer their professional skills pro bono. Significant numbers of people donate blood and marrow despite the discomfort. And every year between 100 and 200 people donate a kidney to a complete stranger. ${ }^{63}$

How much would the supply of kidneys increase if donors were "paid" in the form of contributions on their behalf to charities that they care about? We answer this question in steps. First, we ask what the supply of kidneys would be if donors could be paid in cash. Second, we ask how that supply would be affected if donors' compensation could take only the form of charitable donations to causes they care about.

The first step is that of deriving a supply curve for kidneys in a for-profit market. A back-of-the-envelope calculation is provided here, designed to show how the analysis can be performed and to give a rough estimate of the likely effect of the proposal on the supply of kidneys. As noted, 100 to 200 people yearly donate their kidneys to strangers in return for nothing at all; ${ }^{64}$ suppose here just 100 donors. This statistic allows for an anchoring of the left side of the supply curve. Now suppose that if there was a legal market in kidneys, it would clear at, say, $\$ 100,000$, which would supply 10,000 people per year. ${ }^{65}$ Finally, suppose that the supply curve is linear. If this is the case, then the number of kidneys supplied will be roughly the price divided by 10 plus 100 . For example, at a price of $\$ 2000,300$ kidneys would be supplied. At a price of $\$ 30,000,3100$ kidneys would be supplied.

The second step is to monetize the utility that a person obtains from a charitable benefit. To simplify the problem, imagine a person who wishes to donate $\$ 2000$ to a charitable cause. Such a person should be indifferent between making that donation himself and having an altruism exchange make that donation on his behalf. Thus, the person should be willing to donate a kidney to the altruism exchange if he would be willing to sell his kidney for \$2000. Selling his kidney gives the person $\$ 2000$ that he can use to donate directly to a charitable cause; donating a kidney to the altruism exchange results in a $\$ 2000$ donation by the altruism exchange on behalf of the kidney donor to the same charity. The two can be treated as equivalent from the perspective of the kidney donor. At the $\$ 2000$ price, according to the supply curve, only 300 or so people would be willing to donate.

buffett-giving-pledge-new-members_n_1896882.html.

63. See Transplants by Donor Type, supra note 5.

64. Id.

65. We currently do not have a basis for these figures, so they should be considered hypothetical only, but they are loosely based on a sense of what the market might look like given information about illegal markets and the need for transplants. 
But, of course, the "price" of a kidney is likely to be higher-at least as high as $\$ 100,000$. A person who wishes to donate $\$ 2000$ to a charity in one year might wish to donate another $\$ 2000$ to the same (or different) charity the next year and so on. A person who donates $\$ 2000$ per year might regard this $\$ 100,000$ payment as equivalent to annual donations over the next fifty years (ignoring the time value of money). The donor might thus think of a kidney donation as a way of liquidating his future charitable obligations in one fell swoop. To the extent a large number of people have a preference to donate $\$ 2000$ per year to various charities (and thus would value a charitable payment that would equal the sum of these donations highly), the number of donations in the altruism exchange proposal could be very large.

How large the number of potential donors is will depend on the existing number of people who have a preference for making charitable donations. It appears likely that a sufficient number of people today have a preference to donate $\$ 2000$ per year to charities to provide the same market clearing number of kidney donations as in a for-profit market. Even people who do not ordinarily wish to donate $\$ 2000$ per year to charities, but have a preference to donate less, might respond to the monetary incentives from the altruism exchange proposal. Imagine a demand curve for "coupons" that count as onedollar contributions to one's favorite charity. A person who already donates $\$ 1000$ per year to charity would be indifferent between donating $\$ 1000$ in cash and donating $\$ 1000$ in coupons, and so would treat $\$ 1000$ in cash and \$1000 in coupons equivalently. Suppose one offers such a person another $\$ 1000$ in coupons (bringing the total to $\$ 2000$ ); how much would that person be willing to pay for them? Certainly less than $\$ 1000$, and then the question is what discount that person attaches. Presumably, he will pay less per coupon as the number of coupons increases. If one can derive the effective price of such coupons (which one might be able to do by using data on matching grants, where people pay $\$ 1$ to make a $\$ 2$ contribution), then one will be able to make a more precise prediction as to the effect of the altruism exchange on kidney donations.

\section{Children and Other Close Relations}

Most donors donate kidneys to family members. And, in that category, over $50 \%$ of the donations go to parents, children, siblings, or spouses. ${ }^{66}$

At first sight, it might seem that such people would not increase their rate of donation under these proposals. They seek to donate their kidneys to their loved ones and are unlikely to use an altruism exchange so that they can instead donate their kidneys to strangers.

However, there are two reasons why this proposal would likely increase the supply of kidneys even among close friends or family members. First, the altruism exchange enables those who care about a potential kidney recipient to

66. See Cook \& Krawiec, supra note 1, at Figure 8. This fraction of donations from family members would be even higher if we included the fraction of swapped kidneys that were the result of family-member donations. 
bank altruistic dollars for use in the future. Imagine a parent with a young child who has a disease that will likely require him to need a kidney transplant in the future, perhaps after he has grown up. Most parents would be willing to give up a kidney to save their children from dialysis. But there are barriers to making this transfer. In particular, it is by no means certain that when the disease eventually hits, the parent will still be able to donate, especially in a reciprocal exchange for someone else's kidney. The parent might be too old or ill to supply a healthy enough kidney to the child, or indeed might be dead.

The altruism exchange would enable a parent to donate a kidney today in return for a specific amount of altruism dollars. The parent can then bank these dollars in the altruism exchange for use in the future for a charitable causeincluding the purchase of a kidney for donation to the parent's child when and if the child eventually needs a kidney donation. Assume, conservatively, that there are 1000 parents in the United States every year who find out that their child has some form of kidney disease and, as a result, their child is at high risk of requiring an eventual kidney transplant. If each of these parents were to donate a kidney immediately to ensure the availability of a kidney donation for his or her child in the future, that would increase the supply of kidneys today by 1000. That would be a more than ten-percent increase in the supply of kidneys available for transplant. Now suppose that the child has only a fifty-percent chance of actually facing kidney failure and the need for a transplant. This means that only 500 of these kidneys will require reciprocal donations. The other 500 kidneys donated today effectively become purely altruistic donations that will not require an eventual reciprocal donation in the future-increasing the total supply of kidneys available for those without a close friend or relative willing to donate a kidney. Moreover, even for the 500 kidney donations today that will require eventual reciprocal donations, because these donations are in the future, cures or other medical advances that delay the need for a kidney donation might be discovered in the interim, further expanding the supply of kidneys available for donation without the need for reciprocation.

Second, consider enabling a parent to donate his kidney to an altruism exchange in return for other (non-kidney) transfers to his child or other close relatives. Suppose, for example, that the child needs a liver transplant. The parent cannot donate his liver (or a piece of it) because he suffers from liver disease, but his kidney is healthy. He donates the kidney to the altruism exchange in return for a promise by the exchange to find a liver for the child. It would be a strange sort of organ fetishism if we allowed people to exchange a kidney for a kidney, but not a kidney for a liver.

But the exchange need not be limited to transplants. Suppose that the parent donates his kidney to the altruism exchange in return for (1) funds that are used to finance surgery needed to remove a cancerous tumor from the child's body, (2) funds that are used to finance the child's college education, or (3) funds that would be used to finance an adult child's dry-cleaning business. People might become uneasy as we move from (1) to (3), but even if only 
exchange (1) or (2) is permitted, the lesson is clear: Parents' strong altruism for their children can be harnessed so as to increase the supply of kidneys while also benefiting children who do not need kidney transplants but have other urgent needs.

\section{Other Considerations}

But suppose the arguments listed here are wrong and that creating a broadened definition of altruism exchange does not increase the supply of kidney donations. Establishing an altruism exchange would still enable a person willing to donate a kidney to a friend or relative to donate that kidney to a stranger in return for a promise that the exchange would ensure that someone else in the near future would donate a kidney to the friend or relative. The altruism exchange would solve two problems that limit the effectiveness of kidney exchanges and kidney chains existing today: the danger that a donor will renege on her promise to donate, and the difficulty of matching people.

Under this proposal, the altruism exchange would guarantee a donation to the donor's intended recipient as soon as a matching kidney became available. Even if another donor reneges on her promise to donate, the altruism exchange can simply assign the next available and compatible kidney to the intended recipient. Paired donations, unless simultaneous, cannot guarantee the successful completion of the exchange. A constraint on the size of NEAD chains is that they are susceptible to a donor reneging on her promise, breaking the chain. ${ }^{67}$

Altruism exchanges also improve on matching compared with existing kidney donations. Paired donations face a difficult matching problem. Not only does the donor from the first pair need to match the recipient from the second pair, but the donor from the second pair must match the recipient from the first pair. The probability of a dual match is necessarily lower than a single match. Moreover, absent an organized place for potential donor-recipient pairs to exchange medical information and find one another, search costs are high for matches. Recent innovations, including MatchingDonors, discussed above, might help reduce the search costs. Nonetheless, the dual matching problem remains with paired donations.

NEAD chains reduce matching costs relative to paired donations in that serial matching requires only that the donor in one pair match the recipient in a subsequent pair in the chain. Matching is nonetheless constrained in NEAD chains. A NEAD chain relies on a serial matching of the specific kidney that is available in the chain with potential donor-recipients. Potential donorrecipients that do not match the specific kidney available in the chain will not participate in a specific NEAD chain until their specific matching kidney appears-which might not occur until far into the future, if at all. In comparison, the pool of donors in an altruism exchange more readily allows the matching of a particular recipient with an existing member of the pool, inducing

67. Healy \& Krawiec, supra note 24, at 656-58. 
the donor paired with the recipient to add her name to the pool of donors (which, in turn, can help facilitate more matches in the future).

IV

\section{LEGAL IMPLICATIONS}

We have addressed in passing but have not yet fully confronted the question of whether any of these proposals are lawful under existing statutes and, if not, what legal changes would be needed so that they could be put into effect.

Existing law provides that a person may not transfer (sell) or receive (buy) a kidney in return for valuable consideration, but that a paired-kidney exchange does not violate this prohibition. ${ }^{68}$ Thus, Donor 1 does not legally receive consideration when he transfers his kidney to Recipient 2, even though this transfer is in exchange for Donor 2 transferring her kidney to Recipient 1.

All these proposals would violate this statutory scheme, if literally interpreted. If Donor 1 donates his kidney to Recipient 2 so that Donor 2 donates charitable activity or charity-earmarked money to Recipient 1, Donor 1 receives valuable consideration because charitable activity and charityearmarked money are not kidneys. ${ }^{69}$ It follows that an altruism exchange would also not be allowed to transfer or receive kidneys.

These proposals are arguably consistent with the spirit of the statutory scheme, which seems directed toward allowing kidney transfers when each side (and possibly one side) is motivated by altruism. However, it is unlikely that a court would read the statutory scheme this broadly.

We would amend the statutory scheme so as to allow altruistic exchanges. The amendment would be straightforward. It would provide that when a person donates a kidney in return for a commitment by another person (or institution) to engage in charitable activity (including the donation of charity-earmarked funds), the latter person's behavior does not constitute valuable consideration. Similarly, when a recipient commits to engage in charitable activity (including the donation of charity-earmarked funds) in return for a kidney, the recipient's activity does not constitute valuable consideration. This would legalize twosided altruistic transfers.

To legalize one-sided altruistic transfers, Congress would also need to provide that a transaction involving the transfer of a kidney is lawful if at least one of the parties does not receive or transfer valuable consideration (as defined above). Thus, if Recipient's Benefactor pays Donor to donate his kidney to Recipient, the transaction is legal because Benefactor does not

68. Charlie W. Norwood Living Organ Donation Act, Pub. L. No. 110-144, 121 Stat. 1813 (2007) (codified at 42 U.S.C. $\S \S 273 b, 274$ e (2006 \& Supp. IV 2011)).

69. One should not confuse this case with a distinct setting, in which a donor promises money or other benefits to a charity in return for nothing (or something minimal like recognition). Courts generally hold in this case that the donor does not receive consideration. In the text, we are addressing a different case, in which the donor makes a transfer to a charity in return for someone else making a transfer to a charity. 
receive consideration, although Donor does.

\section{$\mathrm{V}$ \\ CONCLUSION}

We propose that donors be permitted to donate kidneys in exchange for commitments by recipients or their benefactors to engage in charitable activity or to donate funds to charities chosen by donors. By enabling donors to donate kidneys in exchange for other charitable benefits, our proposals should increase the supply of kidneys as well as other charitable benefits. In effect, we are expanding the range of charitable giving by permitting people to convert a kidney donation into charitable benefits that they care about, where they are not otherwise inclined to donate a kidney to a particular person.

One can see this point in another way. Imagine a society in which people were not permitted to donate money to charitable causes, but could provide only goods (such as food to soup kitchens) or services (such as tutoring of poor children). There would be some charitable activity, but not as much as we observe today. When the society starts permitting people to make cash donations, this makes it possible for people to fund charitable activity for others. A person who does not have spare food, or the time to engage in tutoring, can donate money to a charity, which uses the money to buy food or pay a professional tutor. (We could imagine moralists complaining that the introduction of cash would commodify charitable activity, but we are past that stage.) Our proposals further increase the range of opportunity. Under our proposals, donors can donate not just cash, but also kidneys.

But there are limits to how much this can accomplish. Those engaged in one-on-one barters and cash altruistic exchanges must, among other things, contend with the risk of non-performance. How can a kidney donor be assured that the recipient or those who care for the recipient will honor their promise to build a school after the kidney has been transplanted? Alternatively, if those who care for the recipient build the school first, how can they be assured that the donor of the kidney will not renege on the donation? The third proposal introduces altruism exchanges to help ensure that promises on the part of both kidney donors and recipients (and those who care about the recipients) are kept. If one kidney donor reneges on her promise to donate a kidney, the altruism exchange can ensure that the intended recipient of the kidney will obtain the next available compatible kidney. The assurance of performance, in turn, will help induce greater participation among donors and recipients in the altruism exchange. By bringing together a large number of potential kidney donors and recipients, the altruism exchange also increases liquidity and improves the matching of kidney donors with compatible recipients able to meet the altruistic preferences of the donors.

Because transfers of kidneys and payments to charitable causes through an altruism exchange are based on altruism, the altruism exchange avoids concerns about commodification and coercion of the poor. Of course, a market for 
kidneys that relies on profit motive would generate a greater supply of kidneys than these altruism-based proposals. Nonetheless, these proposals could save lives. 